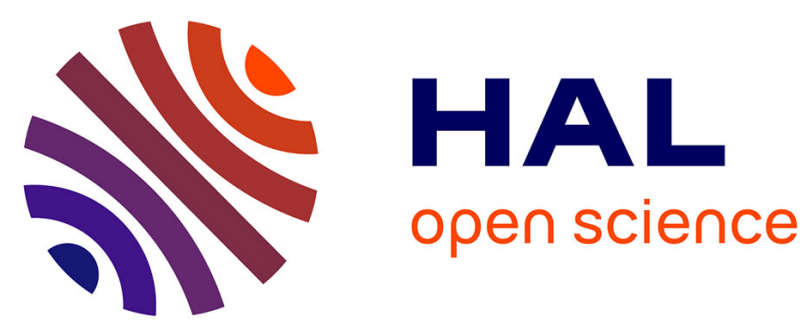

\title{
Low loss coatings for the VIRGO large mirrors
}

\author{
F. Beauville, D. Buskulic, R. Flaminio, F. Marion, A. Masserot, B. Mours, F.
}

Moreau, J. Ramonet, E. Tournefier, D. Verkindt, et al.

\section{To cite this version:}

F. Beauville, D. Buskulic, R. Flaminio, F. Marion, A. Masserot, et al.. Low loss coatings for the VIRGO large mirrors. Optical System Design 2003, Sep 2003, Saint-Etienne, France. pp.483-492. in2p3-00024327

\section{HAL Id: in2p3-00024327 https://hal.in2p3.fr/in2p3-00024327}

Submitted on 24 Mar 2006

HAL is a multi-disciplinary open access archive for the deposit and dissemination of scientific research documents, whether they are published or not. The documents may come from teaching and research institutions in France or abroad, or from public or private research centers.
L'archive ouverte pluridisciplinaire HAL, est destinée au dépôt et à la diffusion de documents scientifiques de niveau recherche, publiés ou non, émanant des établissements d'enseignement et de recherche français ou étrangers, des laboratoires publics ou privés. 


\section{Low loss coatings for the VIRGO large mirrors}

The VIRGO collaboration

F. Beauville ${ }^{1}$, D. Buskulic ${ }^{1}$, R. Flaminio ${ }^{1}$, F. Marion ${ }^{1}$, A. Masserot ${ }^{1}$, L.Massonnet $^{1}$, B. Mours ${ }^{1}$, F. Moreau ${ }^{1}$, J. Ramonet ${ }^{1}$, E. Tournefier ${ }^{1}$, D. Verkindt ${ }^{1}$, O. Veziant ${ }^{1}$, M. Yvert ${ }^{1}$

${ }^{1}$ Laboratoire d'Annecy-le-Vieux de physique des particules Chemin de Bellevue - BP110, 74941 Annecy-le-Vieux Cedex - France

R. Barillé $^{2}$, V. Dattilo ${ }^{2}$, D. Enard ${ }^{2}$, F. Frasconi ${ }^{2 ; 11}$, A. Gennai ${ }^{2}$, P. La Penna ${ }^{2}$, M. Loupias ${ }^{2}$, F. Paoletti ${ }^{2 ; 11}$

${ }^{2}$ European Gravitational Observatory (EGO), Via E. Amaldi, I-56021 Cascina (PI) Italia

L. Bracci ${ }^{3}$, G. Calamai ${ }^{3}$, E. Campagna ${ }^{3}$, G. Conforto ${ }^{3}$, E. Cuoco ${ }^{3}$, I. Fiori ${ }^{3}$, G. Guidi ${ }^{3}$,

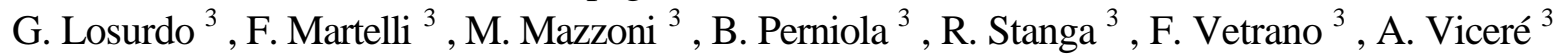
${ }^{3}$ INFN - Sez. Firenze/Urbino Via G.Sansone 1, I-50019 Sesto Fiorentino ; and/or Università di Firenze, and/or Osservatorio Astrofisico di Arcetri Largo E. Fermi 5, I-50125 Firenze; and/or Università di Urbino, Via S.Chiara, 27 I-61029 Urbino, Italia

D.Babusci $^{4}$, G.Giordano ${ }^{4}$

${ }^{4}$ INFN, Laboratori Nazionali di Frascati Via E. Fermi, 40, I-00044 Frascati (Roma) - Italia

J.-M. Mackowski ${ }^{5}$, N. Morgado ${ }^{5}$, L. Pinard ${ }^{5}$ ? , A.Remillieux ${ }^{5}$

${ }^{5}$ SMA - IPNL 22, Boulevard Niels Bohr 69622 - Villeurbanne- Lyon Cedex France

F. Acernese ${ }^{6}$, F. Barone ${ }^{6}$, E. Calloni ${ }^{6}$, R. De Rosa ${ }^{6}$, L. Di Fiore ${ }^{6}$, A. Eleuteri ${ }^{6}$, L. Milano ${ }^{6}$, K. Qipiani ${ }^{6}$, I. Ricciardi ${ }^{6}$, G. Russo ${ }^{6}$, S. Solimeno ${ }^{6}$, M. Varvella ${ }^{6}$,

${ }^{6}$ INFN - sez. Napoli and/or Università di Napoli "Federico II" Complesso Universitario di Monte S. Angelo Via Cintia, I-80126 Napoli, Italia and/or Università di Salerno Via Ponte Don Melillo, I-4084 Fisciano (Salerno), Italia

F. Bondu ${ }^{7}$, A. Brillet ${ }^{7}$, E. Chassande-Mottin ${ }^{7}$, F. Cleva ${ }^{7}$, T. Cokelaer $^{7}$, J.-P. Coulon ${ }^{7}$, B. Dujardin ${ }^{7}$, J.-D. Fournier ${ }^{7}$, H. Heitmann ${ }^{7}$, C. N. Man $^{7}$, F. Mornet $^{7}$, J. Pacheco ${ }^{7}$, A. Pai ${ }^{7}$, H. Trinquet $^{7}$, J.-Y. Vinet ${ }^{7}$

${ }^{7}$ Observatoire de la Côte d'Azur - Département Fresnel Interférométrie Laser pour la Gravitation et l'Astrophysique BP 4229, 06304 Nice Cedex 4 - France

N. Arnaud ${ }^{8}$, M. Barsuglia ${ }^{8}$, M.A. Bizouard ${ }^{8}$, V. Brisson ${ }^{8}$, F. Cavalier ${ }^{8}$, M. Davier ${ }^{8}$, P. Hello ${ }^{8}$, P. Heusse $^{8}$, S. Kreckelberg ${ }^{8}$

${ }^{8}$ Laboratoire de l'Accélérateur Linéaire (LAL),IN2P3/CNRS-Université de Paris-Sud, B.P. 34, 91898 Orsay Cedex - France 


\title{
C. Boccara ${ }^{9}$, V. Loriette ${ }^{9}$, J. Moreau ${ }^{9}$, V. Reita ${ }^{9}$
}

${ }^{9}$ ESPCI - 10, rue Vauquelin, 75005 Paris - France

P. Amico ${ }^{10}$, L. Bosi ${ }^{10}$, L. Gammaitoni ${ }^{10}$, M. Punturo ${ }^{10}$, F. Travasso ${ }^{10}$, H. Vocca ${ }^{10}$

${ }^{10}$ INFN Sezione di Perugia and/or Università di Perugia, Via A. Pascoli, I-06123 Perugia - Italia

\author{
L. Barsotti ${ }^{11}$, S. Braccini ${ }^{11}$, C. Bradaschia ${ }^{11}$, G. Cella ${ }^{11}$, C. Corda ${ }^{11}$, A. Di Virgilio ${ }^{11}$, \\ I. Ferrante ${ }^{11}$, F. Fidecaro ${ }^{11}$, A. Giazotto ${ }^{11}$, E. Majorana ${ }^{11}$,L. Holloway ${ }^{11}$, R. Passaquieti ${ }^{11}$, \\ D. Passuello ${ }^{11}$, R. Poggiani ${ }^{11}$, A. Toncelli ${ }^{11}$, M. Tonelli ${ }^{11}$ \\ ${ }^{11}$ INFN - Sezione di Pisa and/or Università di Pisa, Via Filippo Buonarroti, 2 I-56127 PISA - Italia
}

\author{
L. Brocco ${ }^{12}$, S. Frasca ${ }^{12}$, C. Palomba ${ }^{12}$, P. Puppo ${ }^{12}$, P. Rapagnani ${ }^{12}$, F. Ricci ${ }^{12}$ \\ 12 INFN, Sezione di Roma and/or Università "La Sapienza", P.le A. Moro 2, I-00185, Roma
}

? Corresponding author: pinard@ipnl.in2p3.fr, Phone: 33-4-72-43-26-68, fax: 33-4-72-43-26-79

\begin{abstract}
The goal of the VIRGO program is to build a giant Michelson type interferometer (3 kilometer long arms) to detect gravitational waves. Large optical components (350 mm in diameter), having extremely low loss at $1064 \mathrm{~nm}$, are needed. Today, the Ion beam Sputtering is the only deposition technique able to produce optical components with such performances.

Consequently, a large ion beam sputtering deposition system was built to coat large optics up to 700 mm in diameter. The performances of this coater are described in term of layer uniformity on large scale and optical losses (absorption and scattering characterization).

The VIRGO interferometer needs six main mirrors. The first set was ready in June 2002 and its installation is in progress on the VIRGO site (Italy). The optical performances of this first set are discussed. The requirements at $1064 \mathrm{~nm}$ are all satisfied. Indeed, the absorption level is close to $1 \mathrm{ppm}$ (part per million), the scattering is lower than 5 ppm and the R.M.S. wavefront of these optics is lower than $8 \mathrm{~nm}$ on $150 \mathrm{~mm}$ in diameter. Finally, some solutions are proposed to further improve these performances, especially the absorption level (lower than $0.1 \mathrm{ppm}$ ) and the mechanical quality factor Q of the mirrors (thermal noise reduction).
\end{abstract}

\section{INTRODUCTION}

Detecting gravitational waves is certainly one of the main challenges in physics for the years to come. The Einstein's theory of General Relativity foresees the existence of gravitational waves as a way of propagation of the gravitational field, analogously to the case of electromagnetism. According to the same theory, the gravitational waves arise from the change of mass distribution and propagate in vacuum at the speed of light. The main difficulty in gravitational waves detection lies in the extreme weakness of their interaction with matter. Though more than 80 years have passed from their theoretical prediction, gravitational waves have not yet been detected.

Since the idea of using a laser interferometer as a gravitational wave detector was suggested in the 1960s [1], several full size interferometric detectors are in construction, and particularly VIRGO (a collaborative effort of the CNRS in France and the INFN in Italy, web site http://www.virgo.infn.it/).

Virgo is a gravitational wave detector aiming at the detection of gravitational waves emitted by several galactic and extragalactic astrophysical sources. Among the expected sources of gravitational waves, there are stellar core collapses, the coalescing of binaries made by two compact stars, and rotating neutron stars. The detection of these signals will allow 
getting new fundamental data on the gravitational interaction, on several astrophysical processes and on the dynamics of the universe.

The goal of this program is the construction of a giant Michelson type interferometer with Fabry-Perot cavities in each $3 \mathrm{~km}$ long arm (arm diameter $1.2 \mathrm{~m}$, under ultra-high vacuum). The aim of this experiment is to detect gravitational waves in the frequency range from $10 \mathrm{~Hz}$ to a few $\mathrm{kHz}$. In the Einstein general relativity framework, the effect of the passage of a gravitational wave on a mass distribution is the modulation of the relative distances. Because of the its quadrupolar nature, when a gravitational wave pass through a Michelson interferometer, one of the arms gets longer and the other smaller.

Taking into account the expected distribution of the astrophysical sources, the signal strength is expected to generate a difference of optical path between the two arms of about $10^{-18} \mathrm{~m}$. To avoid that defects in the mirrors can generate in the interferometer a noise level larger than the expected signal, very high quality mirrors are needed.

The total losses at $1064 \mathrm{~nm}$ of each mirror (including absorption, scattering and large-scale wavefront deformation) should not exceed 100 parts per million (ppm).

There are specific constraints on the absorption $(<5 \mathrm{ppm})$ due to the thermal lensing and on the scattering level $(<5 \mathrm{ppm})$ to minimize the noise on the interferometer output, due to the scattered. Moreover, the VIRGO interferometer design imposes very large (diameter $350 \mathrm{~mm}$ ) and heavy optics $(20 \mathrm{~kg})$.

The only deposition technique able to produce components with such optical performances is the Ion Beam Sputtering (IBS). We have demonstrated in the past the capability of this technique to reach very low-loss levels $(<5$ ppm) [2,3]. These performances were obtained on high reflectivity mirrors up to ? $100 \mathrm{~mm}$, which is the larger size that can be coated in our small coater $\left(0.8 * 0.8 * 0.5 \mathrm{~m}^{3}\right)$.

Thus, we are involved in the VIRGO collaboration to take up this challenge according to our skill in high quality optical coatings. To be able to reach the severe VIRGO requirements on ? $350 \mathrm{~mm}$, a new IBS coater was designed and manufactured. In the same time, we have developed special metrology tools able to characterize the optical performances of the coatings on large area: wavefront, scattering, absorption, roughness, and point defect detection.

In the following paragraphs, we will essentially describe in detail the large deposition system we have. Then, the first results obtained on the coatings will be analyzed. The capability of this IBS system to coat large high quality optics will be discussed: this will be demonstrated with the VIRGO mirrors.

\section{IBS COATER DESCRIPTION}

The new IBS system design was defined and optimized with a home-made simulation software [4], which describes precisely the sputtering phenomenon in the IBS process. This software takes into account all the geometrical and electrical parameters. The aim of this simulation is to have, on a diameter of $700 \mathrm{~mm}$, a deposition rate similar to the one we have in the small IBS coater. Furthermore, the possibility to coat two large substrates at the same time is required. The final result of this design work is the coater shown in picture 1 and 2 .

The size of the vacuum chamber is $\mathbf{2 . 4} * \mathbf{2 . 4} * \mathbf{2 . 2} \mathbf{m}^{\mathbf{3}}$ : this is the larger IBS coater in the world at the present time. The sample holder (robot) allows every movements of the substrate inside a circle of $1 \mathrm{~m}$. This is a crucial part regarding the corrective coating procedure [3] (wavefront planarization method).

The coater was installed in a class 1 clean room in 1999. The integration of every equipment necessary for the deposition process has lasted about one year (this has been made exclusively by the SMA group).

Two dry pumps, coupled with two roots, make the primary pumping (a pressure of $8.10^{-3}$ mbar is reached in 30 minutes) and the secondary pumping is performed by four CTI cryopumps. A base pressure of $4.10^{-8}$ mbar is obtained in 3 hours $\left(10^{-6}\right.$ mbar reached in 1 hour $)$. This pumping configuration guarantees a very clean vacuum without hydrocarbon. The vacuum quality is in real time controlled with a residual gas analyzer (quadrupole mass spectrometer). Only water 
vapor is detected after the pumping step, but the corresponding partial pressure is very low ( $\mathrm{P}_{\mathrm{H} 2 \mathrm{O}}<10^{-13}$ mbar). With this clean vacuum, we can prevent the layer contamination and obtain low absorption levels for the coatings.
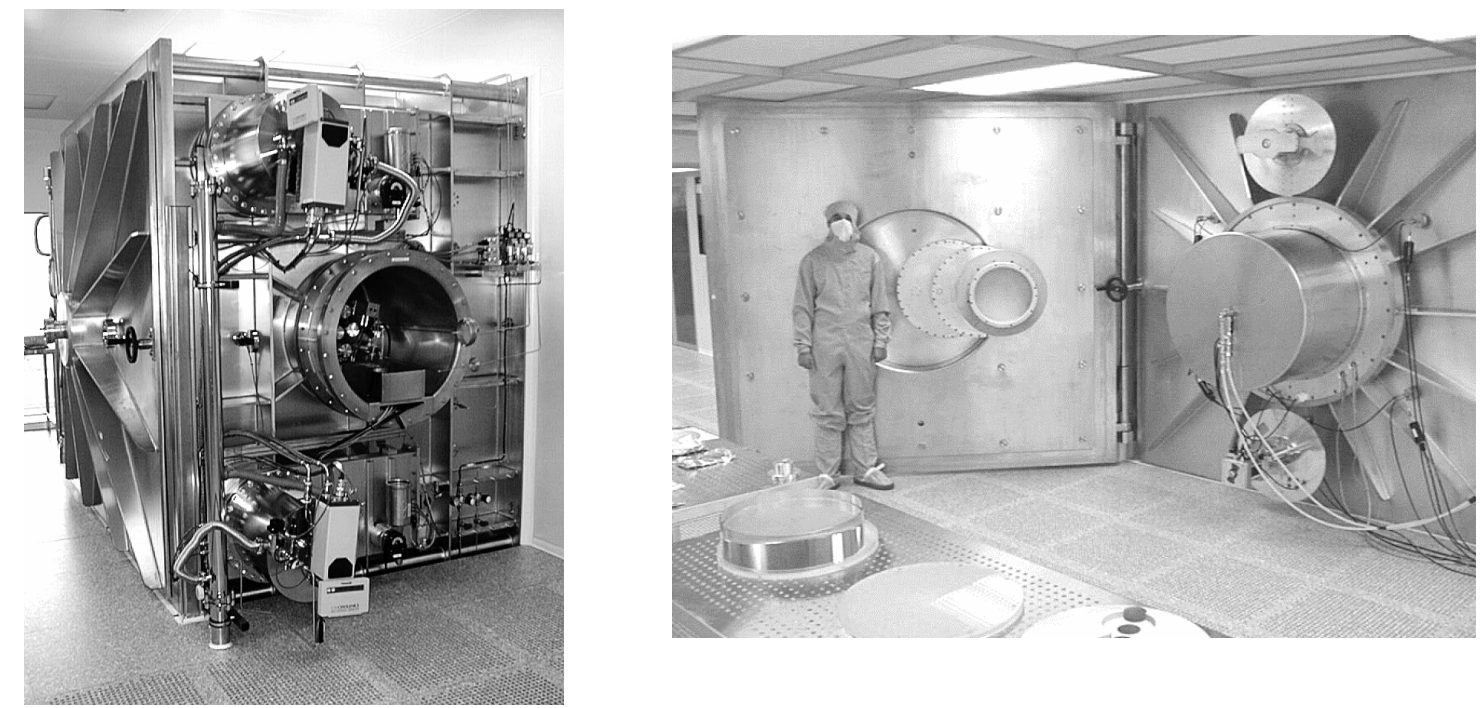

Pictures 1 and 2: IBS deposition system

To have a satisfactory deposition speed, two RF (radio frequency) ion sources are needed. Each source sputters its own ultra-pure targets $\left(\mathrm{Ta}, \mathrm{SiO}_{2}\right)$.

Several reasons have justified this choice instead of classical Kaufman ion sources. First of all, it suppresses the eventual layer contamination due to the tungsten filament, which degrades the layer absorption. Secondly, to realize the quarterwave stacks and the corrective coating, the deposition time is very long (about 100 hours). As the filament lifetime is around 40 hours, the choice of filamentless sources was imperative.

The layer thickness is monitored by four quartz balances, which allow a very efficient in-situ control. Another component we developed is the automatic control command of the coater. It manages the pumping and venting procedure (done with ultra pure dry air) and every step of the deposition process (control of the ion sources, the gas flows, the targets movements).

\section{OPTICAL METROLOGY TOOLS}

The coating metrology is fully part of the global process. In the past, it allowed us to improve rapidly the coating performances and to reach a very high quality level. To avoid contamination of the mirrors which can affect the scattering measurement, all the metrology tools are available in the class 1 clean room, close to the IBS coater.

The VIRGO requirements essentially concern the absorption and the scattering level, the RMS wavefront deformation. All the metrology benches are able to characterize the entire surface of the large VIRGO components $\left(400 * 400 \mathrm{~mm}^{2}\right)$ and to support heavy samples $(40 \mathrm{~kg})$. In this paragraph, we report only the main performances of the optical benches.

$\underline{\text { Scattering and Transmission measurements: }}$ 
The scatterometer is a commercial CASI type instrument able to measure scattering levels lower than $1 \mathrm{ppm}$ (BRDF noise floor of $10^{-9} \mathrm{sr}^{-1}$ ). We can measure the absolute BRDF (Bi-directional Reflectance Distribution function) at one point of the sample (beam size $1 \mathrm{~mm}$ ) as a function of the scattered angle $?_{\mathrm{s}}$.

To have realistic scattering measurements, a BRDF mapping of the entire sample surface is measured to take into account every possible coating defect. This has implied an upgrade of the piloted scatterometer sample holder to realize mappings up to ? $400 \mathrm{~mm}$ and to support heavy samples $(40 \mathrm{~kg})$.

This system can also be used as a very sensitive wattmeter to determine very low transmission values $(\mathrm{T}<1 \mathrm{ppm})$.

\section{$\underline{\text { Absorption measurements: }}$}

We have developed a new absorption bench in collaboration with ESPCI (Paris) able to measure surface and bulk absorption on large sample. It is based on the photothermal deflection technique whose capability to determine very low absorption levels has already been demonstrated [2].

What is remarkable is the sensitivity of this bench at $1064 \mathrm{~nm}: 20 \mathrm{ppb}$ (part par billion) for surface absorption, $30 \mathrm{ppb} / \mathrm{cm}$ for bulk absorption. Measuring the bulk absorption of the silica substrates crossed by the VIRGO laser beam was necessary to check the VIRGO requirements $(A<1 \mathrm{ppm} / \mathrm{cm})$. The result was satisfactory: $A=0.7 \mathrm{ppm} / \mathrm{cm}$.

To reach such a low level, the German company Heraeus, who manufactured all the silica substrates used in VIRGO, has developed in collaboration with ESPCI (Paris) new types of silica (Suprasil $311 \mathrm{SV}$, Suprasil $312 \mathrm{SV}$ ). The OH content is very low $(<<50 \mathrm{ppm})$, the refractive index is homogeneous in all directions and the birefringence is very low $\left(<5.10^{-4}\right.$ $\mathrm{rad} / \mathrm{cm})$.

\section{Wavefront measurements:}

We use a commercial interferometer from ADE Phase Shift (minifiz type interferometer, pupil ? $150 \mathrm{~mm}$, wavelength $1064 \mathrm{~nm}$ ). To measure large wavefront (? $400 \mathrm{~mm}$ ), we have developed in collaboration with a French company (MB Optique) a numerical method called "Stitching Interferometry" [5,6].

The reproducibility (difference between two successive measurement) of this method is $0.4 \mathrm{~nm}$ RMS on ? $400 \mathrm{~mm}$ : this is remarkable regarding the measurement complexity (the reproducibility without stitching is $0.04 \mathrm{~nm}$ RMS on? $150 \mathrm{~mm}$ ).

\section{Roughness and defects detection measurements:}

We use a commercial profilometer MICROMAP which has been modified to characterize large optics. The sensitivity is $0.2 \AA$ RMS. All the VIRGO substrates, polished by the American Company Wave Precision, were measured to check the roughness $(<0.5 \AA \mathrm{RMS})$.

The scattering level is not depending only on the Rayleigh diffraction theory linked to the surface roughness ?. It depends also on the number and the size of the point defects on the surface. We have developed, in collaboration with Micromap, a unique prototype around the profilometer capable to detect small defects (detection threshold? $0,3 \mu \mathrm{m}$ ). We can verify the substrate surface quality (maps on ? $400 \mathrm{~mm}$ ) and also the substrate cleaning procedure, which is a crucial part of our deposition process. This method distinguishes small defects $(0.3-1 \mu \mathrm{m})$, larger defects $(>1 \mu \mathrm{m})$ and scratches.

\section{PRELIMINARY RESULTS}

Our first goal was to find the best deposition conditions (beam current, target angles, gas flows) to obtain the lowest layer absorption.

We worked at first on single layers of $\mathrm{SiO}_{2}$ and $\mathrm{Ta}_{2} \mathrm{O}_{5}$, which are the oxide layers having the best optical properties in the mid-infrared region. The extinction coefficient at $1064 \mathrm{~nm}$ is:

$$
\begin{array}{ll}
\text { - for } \mathrm{SiO}_{2}: & \mathbf{k}=\mathbf{4 1 0}+/-\mathbf{0 . 5} .10^{-7} \\
\text { - for } \mathrm{Ta}_{2} \mathrm{O}_{5}: & \mathbf{k}=\mathbf{4 . 5} 10^{-7}+/-0.5 .10^{-7}
\end{array}
$$

The first quarter-wave multilayer mirrors realized by this deposition system have an absorption of $\mathbf{0 . 6} \mathbf{~ p p m ~ a t ~} 1064 \mathbf{~ n m}$. This is lower than the VIRGO requirement (5 ppm). 
The second step of the coater development was to find the geometrical configuration giving the best layer thickness uniformity. As large substrates are very expensive, we have developed a $350 \mathrm{~mm}$ diameter mounting in which several one inch diameter substrates can be put. Because the large sample motion in the vacuum chamber is a simple rotation, measuring the uniformity along a diameter is enough to have a good idea of the layer uniformity over the entire surface. We looked first at the single layer thickness uniformity (Figure 1).

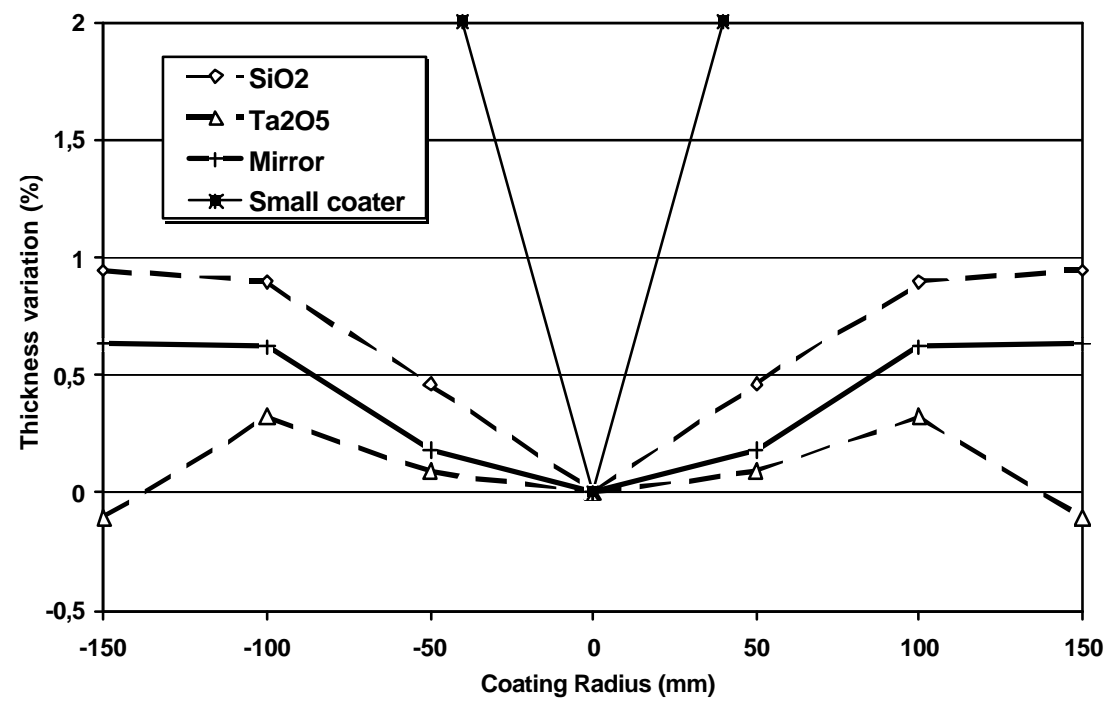

Figure 1: Thickness variation, with respect to the center, as a function of the coating radius

The $\mathrm{SiO}_{2}$ layer is the restrictive factor. Indeed, the uniformity is worse by a factor of 3-4 than that of the $\mathrm{Ta}_{2} \mathrm{O}_{5}$ layer (sputtering particle emission different). To solve this problem, we used a mask between the target and the substrates. Nevertheless, the uniformity obtained on a multilayer mirror is good: $0.6 \%$ on ? 300. What is also remarkable is the improvement obtained between the new large coater and the old small coater (thickness uniformity of $2 \%$ only on ? 80 $\mathrm{mm})$.

The simulation program, which allowed us to determine the coater geometry, predicted a uniformity of $1.33 \%$ on ? $300 \mathrm{~mm}$ (Figure 2).
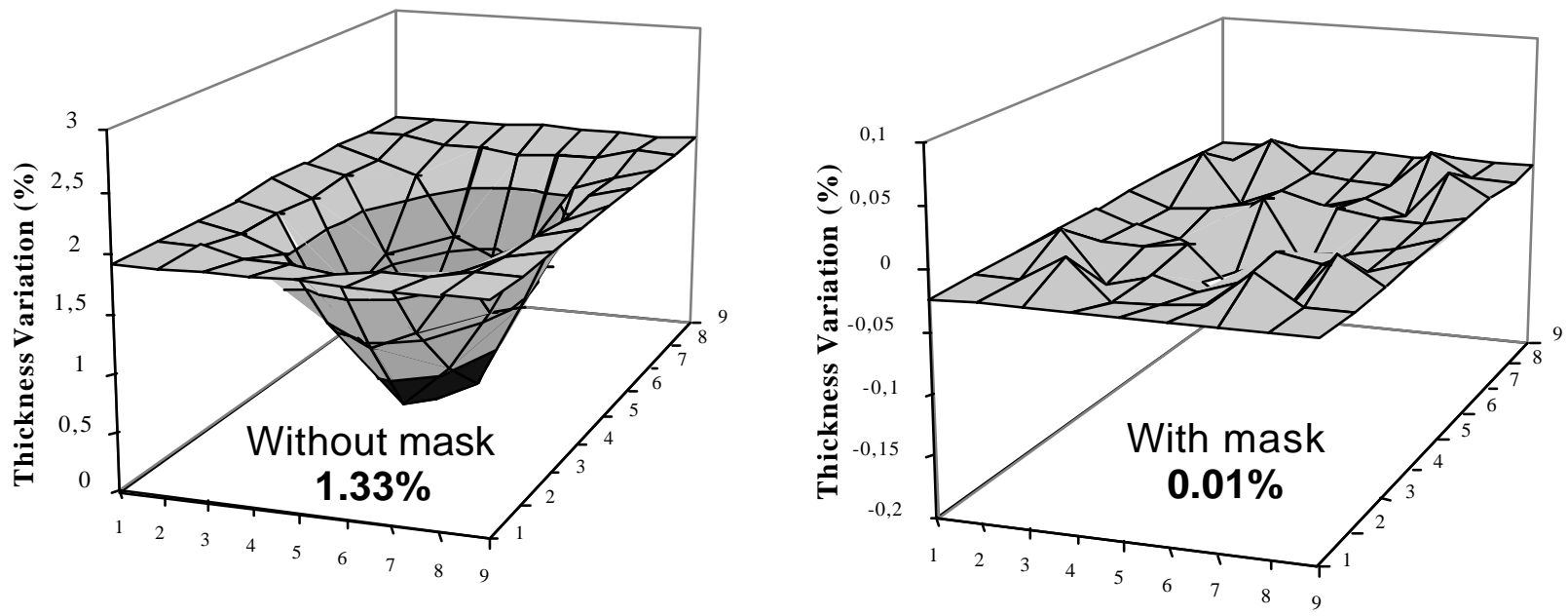

Figure 2: Mirror uniformity simulation on? $300 \mathrm{~mm}$ - Mask efficiency 
Experimentally, the uniformity is twice better. Thus, we can reasonably think that, with the use of masks, the mirror uniformity can be better than $0.01 \%$. This value corresponds to the Virgo requirement for the next mirror generation (wavefront variation around $1 \mathrm{~nm}$ RMS on? $300 \mathrm{~mm}$ ).

As these predictions seemed very promising, the integration of masks in the deposition chamber was tested. At first, we have worked on the monolayer uniformity optimization. The mask shape was numerically calculated for each material and optimized after deposition by successive iterations.

The Figure 3 shows how powerful this method is. For a $\mathrm{Ta}_{2} \mathrm{O}_{5}$ layer, the uniformity goes from $0.6 \%$ on ? $300 \mathrm{~mm}$ to $\mathbf{0 . 2 5 \%}$ on? $700 \mathrm{~mm}$ (with mask $\mathrm{n}^{\circ} 3$ ).

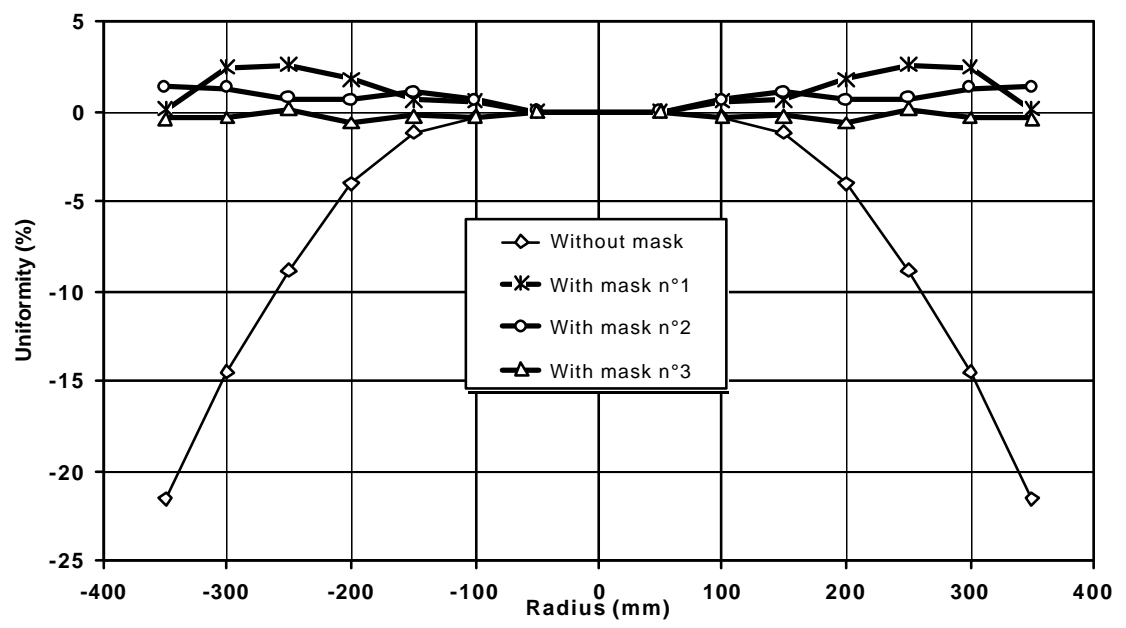

Figure 3: Improvement of a $\mathrm{Ta}_{2} \mathrm{O}_{5}$ single layer uniformity by masking

With this method, we will be able to coat very large surface with a very good uniformity or two substrates at the same time. In the next future, we will implement the masking method to realize multidielectric mirrors.

\section{THE FIRST SET OF VIRGO MIRRORS}

The VIRGO interferometer needs six main mirrors. The $3 \mathrm{~km}$ long Fabry-Perot cavities need four large mirrors (Input and End mirrors, $350 \mathrm{~mm}$ diameter, about 100mm thickness and $20 \mathrm{~kg}$ mass). Because of their dimensions, we have developed new tools to manipulate them between every step of the process in clean conditions with a total safety. Such large components have never been coated in the past, so it was a great challenge for us to succeed. 


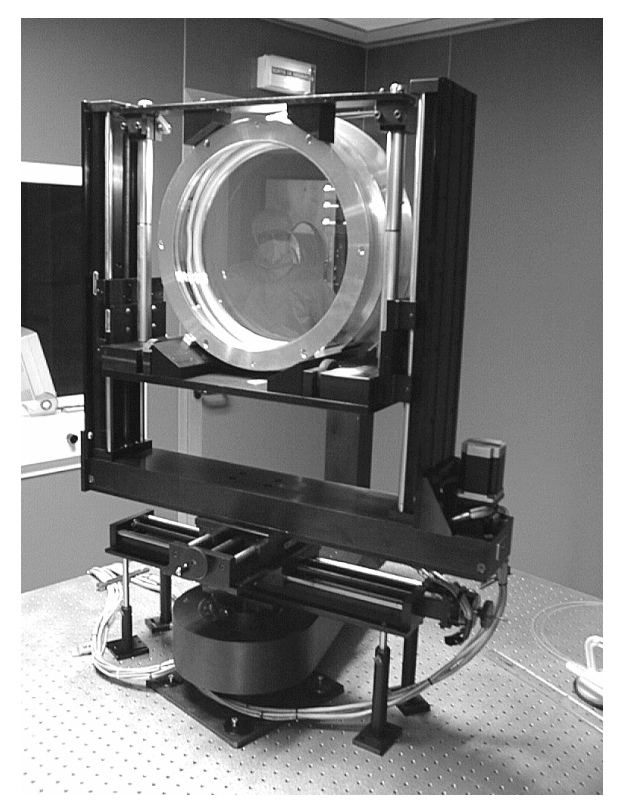

Picture 4: First VIRGO End Mirror during the scattering measurement

The beam splitter is $55 \mathrm{~mm}$ thick, it has a diameter of $230 \mathrm{~mm}$ and a mass of $5 \mathrm{~kg}$. The recycling mirror is $30 \mathrm{~mm}$ thick and it has a diameter of $120 \mathrm{~mm}$.

The first set of the VIRGO mirrors was ready in June 2002 as foreseen by the planning. The picture 4 shows a real VIRGO mirror in its characterization mounting.

Now, the mirror installation on the VIRGO site in Italy is finished. A summary of the optical performances of these large mirrors is shown on the table 1.

The absorption and scattering requirements $(<5 \mathrm{ppm})$ are satisfied for each component, especially for the absorption (in the $1 \mathrm{ppm}$ range). The dispersion in the absorption values only comes from the coating design: the higher the reflectivity the lower the absorption.

Some scattering values are higher than $5 \mathrm{ppm}$, but if we consider only the surface corresponding to the laser beam size, the scattering is in the VIRGO specifications.

\begin{tabular}{|c|c|c|c|c|c|c|c|}
\hline & \multicolumn{2}{|c|}{$\begin{array}{c}\text { Coating Nature } \\
\text { and Clear aperture }(\mathrm{mm})\end{array}$} & \multicolumn{2}{|c|}{ RMS Wavefront (nm) } & \multirow{2}{*}{$\begin{array}{c}\text { Average } \\
\text { Absorption } \\
\text { (ppm) }\end{array}$} & \multirow{2}{*}{$\begin{array}{c}\text { Average } \\
\text { Scattering } \\
(\mathrm{ppm})\end{array}$} & \multirow{2}{*}{ Transmission } \\
\hline & Side A & Side B & Side A & Side B & & & \\
\hline $\begin{array}{l}\text { End Mirror } \\
\quad n^{\circ} 1\end{array}$ & - & $\begin{array}{c}\mathrm{HR} \\
\text { ? } 330 \mathrm{~mm}\end{array}$ & $\begin{array}{c}3.9 \\
? 150 \mathrm{~mm}\end{array}$ & $\begin{array}{c}\mathbf{3 . 8} \\
? 150 \mathrm{~mm}\end{array}$ & $\begin{array}{rl} & \mathbf{0 . 6 7} \\
? & 150 \mathrm{~mm}\end{array}$ & $\begin{array}{c}4 \\
? 150 \mathrm{~mm}\end{array}$ & $42.9 \mathrm{ppm}$ \\
\hline $\begin{array}{l}\text { End Mirror } \\
\quad \mathrm{n}^{\circ} 2\end{array}$ & - & $\begin{array}{c}\mathrm{HR} \\
\text { ? } 330 \mathrm{~mm}\end{array}$ & $\begin{array}{c}\mathbf{2 . 8} \\
? 150 \mathrm{~mm}\end{array}$ & $\begin{array}{c}3.4 \\
? 150 \mathrm{~mm}\end{array}$ & $\begin{array}{l}\quad \mathbf{0 . 6 9} \\
? 150 \mathrm{~mm}\end{array}$ & $\begin{array}{c}\mathbf{6 . 5} \\
? 150 \mathrm{~mm}\end{array}$ & 38.3 ppm \\
\hline $\begin{array}{c}\text { Input } \\
\text { Mirror } n^{\circ} 1\end{array}$ & $\begin{array}{c}\mathrm{HR} \\
\text { ? } 200 \mathrm{~mm}\end{array}$ & $\begin{array}{c}\text { AR } \\
? 200 \mathrm{~mm}\end{array}$ & $\begin{array}{l}2.6 \\
? 60 \mathrm{~mm}\end{array}$ & $\begin{array}{l}3.8 \\
? 60 \mathrm{~mm}\end{array}$ & $\begin{array}{l}1.25 \\
? 60 \mathrm{~mm}\end{array}$ & $\begin{array}{c}5 \\
? 60 \mathrm{~mm}\end{array}$ & $11.80 \%$ \\
\hline
\end{tabular}




\begin{tabular}{|c|c|c|c|c|c|c|c|}
\hline $\begin{array}{c}\text { Input } \\
\text { Mirror } n^{\circ} 2\end{array}$ & $\begin{array}{c}\mathrm{AR} \\
? 200 \mathrm{~mm}\end{array}$ & $\begin{array}{c}\mathrm{HR} \\
\text { ? } 200 \mathrm{~mm}\end{array}$ & $\begin{array}{c}2.6 \\
? 60 \mathrm{~mm}\end{array}$ & $\begin{array}{c}2.5 \\
? 60 \mathrm{~mm}\end{array}$ & $\begin{array}{c}1.20 \\
? 60 \mathrm{~mm}\end{array}$ & $\begin{array}{c}8 \\
? 60 \mathrm{~mm}\end{array}$ & $11.66 \%$ \\
\hline $\begin{array}{l}\text { Recycling } \\
\text { Mirror } n^{\circ} 2\end{array}$ & $\begin{array}{c}\mathrm{HR} \\
\text { ? } 110 \mathrm{~mm}\end{array}$ & $\begin{array}{c}\mathrm{AR} \\
? 110 \mathrm{~mm}\end{array}$ & $\begin{array}{c}\mathbf{1 . 8} \\
? 60 \mathrm{~mm}\end{array}$ & - & $\begin{array}{c}\mathbf{0 . 6 6} \\
\text { center }\end{array}$ & $\begin{array}{c}4 \\
? 60 \mathrm{~mm}\end{array}$ & $7.97 \%$ \\
\hline $\begin{array}{c}\text { Beam } \\
\text { Splitter } n^{\circ} 1\end{array}$ & $\begin{array}{c}\mathrm{AR} \\
? 210 \mathrm{~mm}\end{array}$ & $\begin{array}{c}\mathrm{HR} \\
\text { ? } 210 \mathrm{~mm}\end{array}$ & $\begin{array}{c}3.9 \\
? 100 \mathrm{~mm}\end{array}$ & $\begin{array}{c}\mathbf{5 . 4} \\
? 120 \mathrm{~mm}\end{array}$ & $\begin{array}{c}\mathbf{1 . 3 5} \\
\text { center }\end{array}$ & $\begin{array}{c}\mathbf{5 . 5} \\
? 100 \mathrm{~mm}\end{array}$ & $49.8 \%$ \\
\hline
\end{tabular}

Nota $: H R=$ High Reflectivity, AR = Anti Reflective

Table 1 : Optical performances of the first set of VIRGO mirrors

Another remarkable result concerns the flatness of these large components. The " $8 \mathrm{~nm}$ RMS on ? $150 \mathrm{~mm}$ " requirement on the wavefront is always satisfied. Nevertheless, we found that the limiting factor of the wavefront flatness is the substrate. We checked (Figure 4) that the RMS flatness value is the same with or without coating (Before: $3.38 \mathrm{~nm}$

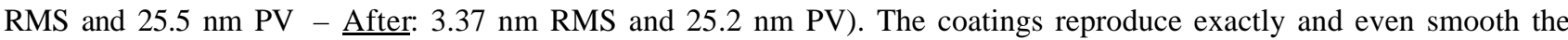
substrate surface (Figures 1 and 3).

As the polishers can not guarantee every time better wavefronts, the only solution is to correct the substrate surface before deposition by the "Corrective Coating" technique [7].

An other Virgo requirement we had to satisfy is the finesse inequality between the two Fabry-Perot cavities: $(\mathrm{Df}<1 \%)$. To fulfill this requirement, the cavity mirrors must have transmission values as close as possible. For instance, the difference between the two Input Mirrors transmission must be lower than $0.2 \%$.
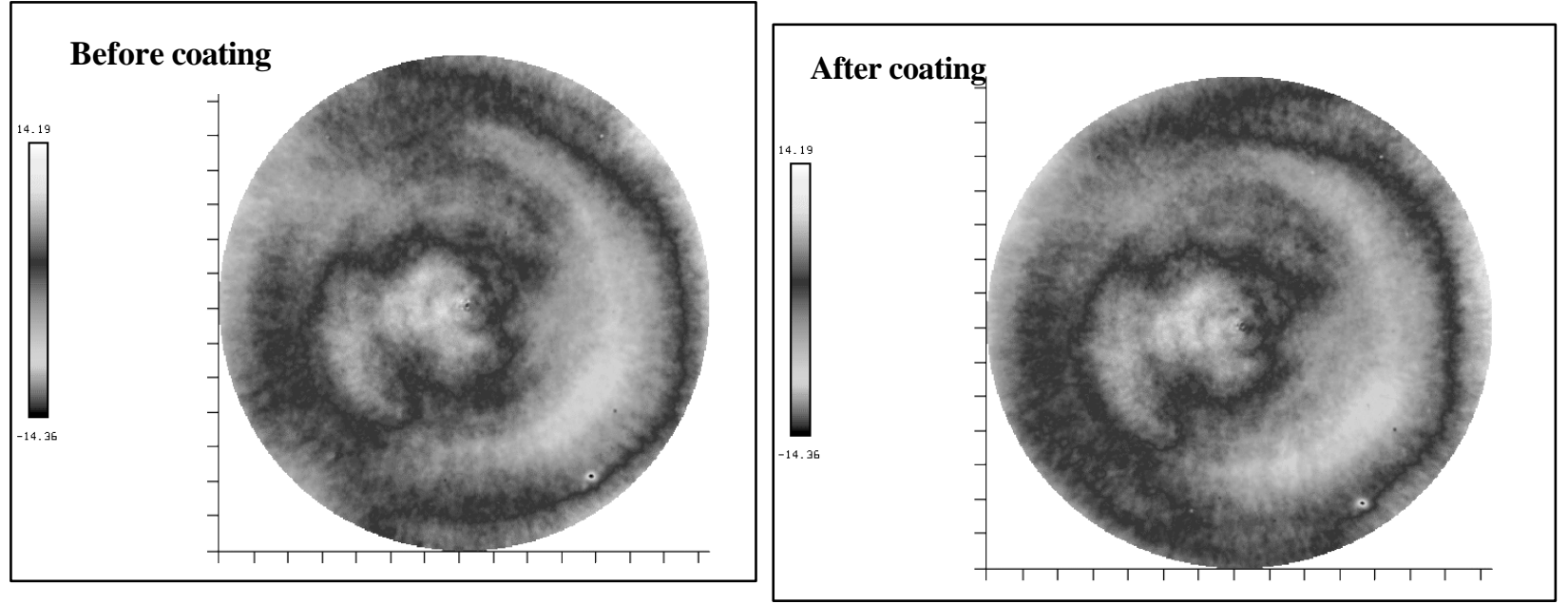

Figure 4: Wavefront on ? $150 \mathrm{~mm}$ of a Virgo Input Mirror before and after coating

\section{CONCLUSION AND PERSPECTIVES}

A new large IBS coater was manufactured to realize low-loss coatings on very large optics (? $350 \mathrm{~mm}$ ). The reproducibility of the process is really good $(<0.3 \%)$. The layer uniformity is better than expected by simulation and the losses at $1064 \mathrm{~nm}$ are also in the expected ranges: $<1 \mathrm{ppm}$ of absorption, $<5 \mathrm{ppm}$ of scattering (1-inch mirrors). As foreseen by the VIRGO planning, the first set of VIRGO mirrors (6 components) was coated. The optical performances of these optics fulfilled the VIRGO requirements. The mirror installation on the VIRGO site is in progress. 
In a very close future, new generations of mirrors with better performances will be necessary to enhance the interferometer sensitivity. Several programs using interferometric detectors of gravitational waves (VIRGO as well as the American project LIGO) are already waiting for the next mirrors generation.

Three main R\&D directions will be investigated in the next future.

The first one concerns the absorption. Our goal is to obtain absorption levels lower than $0.1 \mathrm{ppm}$. Reducing the thermal noise of the mirrors will increase the VIRGO sensitivity in the low frequency domain. Beside an important R\&D work on the coating materials themselves, we intend to carry out a study on the impurities coming from the polishing.

Another key factor increasing the thermal noise is the Quality Factor Q of the coated mirrors (intrinsic mechanical dissipation). The substrate quality factor could be decreased by more than two orders of magnitude by the coating presence. We have already started a collaboration on this subject with the LIGO community. New materials, having better mechanical behavior, will be studied. The goal is to improve the $\mathrm{Q}$ factor by one or two decades without affecting too much the optical properties.

Finally, we will apply the "Corrective Coating" technique, we have developed in the past for the coatings, to the polished substrates. The aim is to reach wavefront flatness in the nm range.

\section{REFERENCES}

[1] M.E. Gertsenshtein and V.I. Pustovoit ; Soviet Physics - JETP 16, 433 (1962)

[2] L. Pinard, P. Ganau, J.M. Mackowski, C. Michel, M. Napolitano, E. Vireton, A.C. Boccara, V. Loriette, H. Piombini ; "95'Optical Interference Coatings", Tucson, Technical Digest Vol. 17, p 200-203 (1995)

[3] J.M. Mackowski, L. Pinard, L. Dognin, P. Ganau, B. Lagrange, C. Michel, M. Morgue ; “98' Optical Interference Coatings", Tucson, USA, Technical Digest Vol. 9, p 18-20 (1998)

[4] L. Dognin, PhD dissertation, Université Claude Bernard Lyon I France, (1997)

[5] M. Bray ,SPIE Vol.3739, p 259-273 (1999)

[6] M. Bray, SPIE Vol 4451, H. Philip Stahl (Ed.), (2001)

[7] J.M. Mackowski, L. Pinard, L. Dognin, P. Ganau, B. Lagrange, C. Michel, M. Morgue; Optical and Quantum Electronics, Vol.31, n5/7, p.507-514, (1999) 